\title{
O trabalho em redes e grupos de colaboração em pesquisa: desafios contemporâneos
}

\author{
Ruth Bernardes Sant'Ana*
}

\section{Resumo}

O artigo apresenta uma reflexão sobre colaboração interuniversitária em redes e grupos nacionais e internacionais de pesquisa na contemporaneidade, com ênfase no seu valor, nos seus impasses e nos desafios impostos às pessoas e aos grupos participantes. $\mathrm{O}$ trabalho parte do suposto de que cenário acadêmico brasileiro exige do professor pesquisador o ajuste dos interesses pessoais aos coletivos de pesquisadores e, ao mesmo tempo, a resposta às exigências advindas do modelo concorrencial que orienta a produção científica na contemporaneidade. Tomando isso em consideração, busca-se subsidiar os interessados na escolha das modalidades de pesquisa colaborativa e dos tipos de projetos, contribuir para a organização da divisão do trabalho no interior das equipes de pesquisa e, quem sabe, no encorajamento de coletivos de pesquisadores a empreenderem projetos colaborativos. Tendo como referencial metodológico a análise de redes sociais, a pesquisa valeu-se de estudos bibliográficos e de reflexóes sobre a prática cotidiana da pesquisa em grupo no âmbito da produção científica universitária, inclusive a partir da inserção do autor deste artigo em um coletivo voltado à constituição de uma rede interuniversitária de investigação em educação.

Palavras-chave: Redes de pesquisa. Colaboração científica. Universidade. Internacionalização.

* Doutora em Psicologia Social pela Pontifícia Universidade Católica de São Paulo (PUC/SP). Professora do Departamento de Psicologias e do Mestrado em Educação na Universidade Federal de São João Del-Rei (UFSJ). 


\section{Introdução}

Este artigo apresenta uma reflexão decorrente da minha participação em discussôes formais ou informais sobre a colaboraçáo coletiva em pesquisa (em grupo e em rede de pesquisadores) na comunidade acadêmica. Recentemente, depois de ter empreendido um grande esforço no trabalho de constituição de uma rede de colaboraçấo nacional/internacional de pesquisa sobre juventude(s) e educação ${ }^{1}$, senti a necessidade de apresentar uma reflexão sobre em que consiste esse tipo de trabalho colaborativo na contemporaneidade, seu valor, seus impasses e os desafios impostos às pessoas e grupos participantes.

Parto do suposto de que o modelo dominante no cenário acadêmico brasileiro exige o ajuste dos interesses pessoais aos coletivos de pesquisadores e, ao mesmo tempo, a resposta às exigências advindas do modelo concorrencial que orienta a produçáo científica na contemporaneidade. Apresento as saídas que visualizo para a constituição e o desenvolvimento de projetos de pesquisa partilhados em Ciências Humanas e Sociais e Educação e para lidar com as tensóes que esse modelo impốe aos envolvidos em redes e grupos de pesquisa. Concebo que uma reflexão prévia acerca dos dilemas mais comum nesse tipo de empreendimento de pesquisa pode orientar os pesquisadores na escolha das modalidades de pesquisa, dos tipos de projetos e na correspondente divisão do trabalho no interior das equipes de pesquisa, algo para o qual a reflexão aqui apresentada pode contribuir.

O texto não consiste em um relato de experiência, mas, sim, na exposição das elaboraçóes teóricas engendradas em função de meu envolvimento em diferentes coletivos de discussão sobre o tema. O seu objetivo maior é refletir em termos de avanços, limitaçóes, conflitos e consensos, sobre o compartilhar pesquisa em rede e grupos, com enfoque em coletivos acadêmicos de pesquisadores/estudantes da graduação e pós-graduação, das ciências humanas e sociais e educaçáo.

Por isso, para os objetivos deste artigo, o debate abrange as seguintes questóes: $\mathrm{O}$ que significa a colaboração de pesquisadores/estudantes em redes/grupos nacional/ internacional em termos acadêmicos? Quais "formatos" essa colaboração pode assumir em ciências humanas e sociais, sobretudo no domínio da educação? Quais desafios são impostos aos participantes do trabalho em rede de pesquisa na contemporaneidade? Como o modelo (concorrencial e centrado nos resultados) que referencia as políticas públicas de pesquisa atualmente afeta o comportamento de indivíduos e grupos no interior de coletivos colaborativos?

Parto da consideração de que a colaboração entre redes e grupos sociais se tornou uma das figuras-chave do movimento histórico de "globalização" das sociedades 
contemporâneas, englobando setores da vida social como a formação profissional, a política e o desenvolvimento da tecnologia. Para Castells (1999, p. 497), as redes constituem "a nova morfologia social de nossas sociedades, e a difusão da lógica de redes modifica de forma substancial a operação e os resultados dos processos produtivos e de experiência, poder e cultura". A organização de pessoas e da produção de bens materiais e simbólicos em rede não é algo novo na história; porém, nos últimos decênios uma base material (um enorme desenvolvimento de tecnologias de comunicação) tem facilitado a sua penetração na estrutura social de uma maneira nunca vista antes (CASTELLS, 1999).

No mundo globalizado, a produção de bens materiais e simbólicos em coletivos amplos e desterritorializados geograficamente, facilitada pela disseminaçáo das novas tecnologias de comunicação hoje existentes, envolve novas formas de intercâmbio social que se ligam às exigências políticas e econômicas de integração e competitividade dos países no "mercado internacional" próprias ao capitalismo hegemônico na atualidade (alguns desdobramentos dessas exigências no campo da pesquisa serão tocadas aqui, adiante). Tais demandas supóem a regulação das economias segundo as regras de eficiência e eficácia importadas dos países em posição política dominante na definição do jogo concorrencial em escala mundial. Os países e os diferentes conglomerados econômicos que ali se movimentam realizam participação simultânea em redes transitórias ou permanentes que confluem para a manutenção ou ampliação do poder econômico, político e cultural dos seus integrantes.

No interior dessa dinâmica societária, atualmente é voz corrente a valorização da constituição de redes de colaboração interuniversitárias na produção de conhecimento com vistas à ultrapassagem de fronteiras institucionais, regionais e nacionais tidas como limitadoras da compreensão da realidade. Como consequência, ganha importância acentuada no discurso acadêmico a formação de redes científicas quando comparada a pesquisadores que, no máximo, realizam pesquisa com seus alunos. Porém, embora a valorização da pesquisa colaborativa esteja em relevo tanto nas agências de fomento quanto nas universidades, sobretudo nas discussóes sobre a produção do conhecimento na pós-graduação, os desafios para a sua constituição ainda são enormes.

Um breve olhar sobre o assunto indicou que a discussão sobre a temática da colaboração interuniversitária do ponto de vista das políticas públicas tem como referência mais ampla dois enfoques: a internacionalização da pesquisa e a formação acadêmica de pesquisadores/alunos que transcendam os saberes particulares de seus domínios disciplinares, sobretudo na pós-graduação. Pelo enfoque da internacionalização, discutem-se fundamentalmente questôes de estratégia, produtos, 
impacto, financiamento, mobilidade internacional e nacional de estudantes/pesquisadores etc. No enfoque da formação acadêmica, aparece o estímulo ao desenvolvimento de rede de pesquisa, aos pesquisadores (e grupos) tidos como capazes de produçáo de inovaçáo de conhecimento e de tecnologia, bem como da promoçáo da socializaçáo do conhecimento para as novas geraçóes de estudantes. Portanto, a colaboração é entendida como uma condição fundamental da pesquisa e da formação de pesquisadores na sociedade contemporânea, embora as condições concretas de sua realização não sejam fáceis, principalmente para os pesquisadores com uma grande carga de trabalho em ensino, gestão acadêmica e extensão universitária.

A concepção mais consensual quanto ao seu sentido e à finalidade de organização de coletivos de pesquisadores/alunos em redes/grupos é aquela segundo a qual o trabalho partilhado de pesquisa busca responder à necessidade de superação da fragmentação nos processos de produção e socialização do conhecimento, inclusive pela adoção de abordagens inter e transdisciplinar. Entretanto, essa concepção é atravessada pelos elementos subjacentes à politicas públicas de ciência e tecnologia (e seus desdobramentos nas políticas das agências de fomento) em suas apropriaçóes diferenciadas pelo mundo acadêmico (das universidades e comunidades de pesquisadores), ocasionando diferentes lógicas de ação individual e coletiva.

\section{A dimensão política do trabalho de pesquisa partilhado: lógicas de ação individual e coletiva}

Podemos afirmar que, em um plano geral, as políticas de colaboração podem ser concebidas como um dispositivo a serviço da ampliação da experiência de pesquisadores/estudantes no âmbito da graduação e da pós-graduação, cujo alvo maior é fomentar novos conhecimentos por meio de investigaçóes de qualidade e forte impacto acadêmico e social. Porém, em um plano específico, o da interação dos pesquisadores entre si, com as universidades e com os órgáos do fomento, e vice-versa, nem sempre as condições institucionais são favoráveis à transposição do plano geral em açôes específicas capazes de concretizá-los efetivamente. Mesmo nas melhores condições, a divisão do trabalho para a sua realização é um desafio não desprezível, do ponto de vista técnico e político.

Assim, um olhar sobre a dimensão política do empreendimento da colaboração entre os atores/agências, no aqui e agora do trabalho coletivo, mostra-nos o cruzamento de diversas lógicas de açấo individual e coletiva, das mais instrumentais e estratégicas às mais comprometidas com a resolução de questôes e problemas sociais. Se o investimento no desenvolvimento de pesquisa colaborativa é meramente uma escolha 
da estratégia institucional, este poderia ser subsumido ao esforço para a mera aquisição ou ampliação de posiçáo de prestígio e poder na disputa no ranking de classificação universitária pelas agências de avaliação. Esse tipo de lógica institucional, segundo Marrara (2007), é exemplificado pelo modelo "anglo-saxônico" da internacionalização da universidade, que, diante das exigências governamentais de inserção dos programas da pós-graduação no "mercado internacional", orienta-se mais pela busca de promoçáo de status institucional e por interesses financeiros e políticos do que pelo interesse em colaborar efetivamente para o desenvolvimento científico e educacional. As açôes institucionais desse modelo incluem "cursos internacionalmente populares, pela organização de eventos de porte internacional, pela atraçáo de alunos e pesquisadores estrangeiros ou pelo grande número de publicaçóes dos pesquisadores da casa em periódicos internacionais" (MARRARA, 2007, p. 248).

A meu ver, para além da intençáo pura e simples das universidades na manutenção de seus interesses financeiros e políticos, existe a obrigação de competir por recursos escassos, em meio a um processo de avaliaçáa externa que introduz quase sempre novas exigências quando a maioria das universidades atinge os critérios para melhoria de sua posição no ranking. Como não há verbas para contemplar todas as demandas, os critérios de excelência são revistos para excluir uma parte dos pretendentes aos financiamentos de pesquisa. Pude assistir a avaliação da pósgraduação em Educação de uma universidade portuguesa entre 2007 e 2008, ocasiáo em que pude observar os representantes da comissão europeia fazerem exigências estranhas no tocante aos critérios de "internacionalização dos cursos", cuja clientela é originária de países lusófonos. Por exemplo: membros da comissão faziam uso da língua inglesa ao inquerirem os alunos, exigiam respostas em inglês e demandavam que uma parte dos cursos fosse ministrada nesta língua, além de parecerem valorizar somente artigos publicados em inglês. Entre outras coisas, isso me mostrou que, em um contexto de enorme dependência dos recursos vindos desse tipo de fonte de financiamento de pesquisa, a sobrevivência da universidade se torna ameaçada. Por isso, devemos analisar esse tipo de situação com cautela antes de considerar tudo puramente como escolhas estratégicas de agências/atores em situação de concorrência no mercado.

Quando o olhar busca as lógicas da açáo que se manifestam na atividade cotidiana dos pesquisadores, é possível perceber que isso depende de fatores de ordem institucional, acadêmica, grupal, individual etc. Isso significa que as açôes dos atores dependem de como eles lidam com as pressôes que sofrem em cada um dos coletivos institucional e acadêmico do qual fazem parte, de maneira que um mesmo ator pode agir por bases em lógicas discordantes entre si, ou integrarem de diferentes maneiras essas lógicas. 
Podemos recorrer à teoria de subjetividade de Dubet (1994) para compreender esse tipo de posicionamentos dos atores diante das exigências de produção de conhecimento científico. Para o autor, na contemporaneidade, encontramos uma fragmentação dos princípios que orientam as experiências na vida social de modo que os atores e a instituiçôes sociais não se orientam por uma lógica única e por uma definição fixa das condutas. Para ele, a dinâmica da vida social favorece que os atores adotem simultaneamente diversos pontos de vista sobre os acontecimentos e sobre as atitudes dos outros, em um processo no qual acabam por combinar lógicas e princípios diversos, muitas vezes opostos.

Faço a transposição do raciocínio de Dubet (1994) para o caso do docentepesquisador para mostrar que este pode lidar com os apelos "produtivistas" presentes no meio acadêmico, de modo a combiná-los ou não com um trabalho comprometido com a resoluçáo de questōes sociais, já que a lógica da produtividade não é sempre inteiramente coerente com aquela de um trabalho mais profundo sobre as questóes sociais. Por exemplo: os prazos exíguos para publicação podem colidir com o tempo de maturação que as questôes sociais geralmente exigem. A valorização dos projetos financiados pode levar o pesquisador a pular de um projeto a outro sem ter explorado devidamente o que o trabalho já acumulado poderia oferecer de contribuição para o avanço do conhecimento.

Conforme Dubet (1994), quando a lógica da estratégia domina o ator, este busca realizar seus interesses particulares num universo relacional cuja imagem é a competição em um mercado no qual os partícipes do jogo concorrencial desenvolvem recursos de adaptação para lidar com as regras do jogo estabelecido. As relaçóes sociais são definidas em termos de concorrências, de rivalidades e de tensóes entre os interesses individuais e os coletivos, de alianças e conflitos entre os atores, de modo que o outro pesquisador pode ser tanto um adversário quanto um aliado, a depender do que se encontra em jogo. Todavia, é comum que outra lógica também se manifeste, em maior ou menor grau, e o ator se posicione criticamente frente à cultura institucional naquilo que compreende como falta de sentido ou de autonomia. Desse modo, os indivíduos mantêm uma relativa distância em relação ao sistema, em movimentos de concordância, de negação (parcial) e de adesão crítica ao jogo estabelecido. Integraçáo e resistência, competição e colaboração fazem parte das dinâmicas dos indivíduos, grupos e instituiçôes diante das exigências que orientam as políticas acadêmicas.

De qualquer maneira, na busca por compreender as lógicas de ação que orientam as ações dos participantes de um coletivo de pesquisa em termos de engajamento é preciso não apenas indagar como os atores combinam as diversas lógicas que orientam o trabalho de produção do conhecimento, relacionando suas experiências 
às condiçōes oferecidas pelo sistema, mas também considerar que a compreensão dos modos de participação e de todas as possíveis consequências das escolhas feitas pode não ser totalmente clara para todos os que vivem essa experiência. Por isso, faz-se necessário perguntar: qual seria a participação desejada para o tipo de empreendimento pretendido? Quem deseja participar realmente? Que resultados são esperados por cada um dos participantes? Quem possui o poder de controlar o trabalho da equipe? Em certos contextos, sob o jogo do prestígio e da influência, isso pode ser algo flutuante e de difícil resposta, já que alguns podem ser beneficiados pelo trabalho de outros por meio de acordos (abertos ou tácitos) em que "papagaio come milho, periquito leva a fama" - o que pode afetar negativamente o trabalho coletivo.

Assim, o processo de colaboração em pesquisa implica o desafio de ajudar a constituir um coletivo de trabalho em que o compromisso com a colaboração efetiva domine as outras lógicas, de maneira a garantir a integração de indivíduos ou grupos à rede de pesquisa e, também, fazer com que o coletivo seja capaz de lidar com as divergências e conflitos no seu interior, em um movimento dialógico e de respeito. Como a pesquisa conjunta é sempre atravessada pela tensão que envolve a produção de conhecimento e a resoluçáo dos problemas práticos para que ela se efetive, faz-se necessário o máximo de explicitação sobre o lugar de cada um na divisão de trabalho, como forma de impedir mal-entendidos, de modo que os coletivos possam dar conta de integrar as diferenças existentes em seu interior com flexibilidade.

Por isso, compreendo a pesquisa colaborativa interuniversitária como um processo de traduçáo dos diferentes interesses dos participantes em um interesse comum. Isso envolve interaçáo e aprendizagem mútua em um processo relacional em que os participantes de pesquisa definem seus papéis e colocam em ação formas diferenciadas de engajamento, ao mesmo tempo em que colaboram com os outros em nome de um emprendimento coletivo. Portanto, as condições para a realização da parceria remetem à integração e à vontade dos parceiros de ultrapassagem das assimetrias porventura existentes por meio da troca de experiências, do diálogo acerca dos diferentes interesses em jogo, além do reconhecimento e da mobilização dos saberes de cada um.

Outra dimensão se revela a partir do lugar que um domínio de conhecimento ocupa na sociedade, em termos de valorizaçáo social e econômica. As agendas e campos de pesquisa reconhecidos como importantes para o desenvolvimento tecnológico, ao abarcarem propriedades intelectuais e potencialidades de incremento da produção de mercadorias e serviços voltados para a troca econômica, comumente são objetos de disputa pelo controle da produçáo científica entre os líderes dos grupos de pesquisadores nela envolvidos (KREIMER, 2010). 
Quando refletimos acerca das relaçóes tecidas no campo internacional, no interior dos agrupamentos de pesquisadores voltados para campos e objetos de pesquisa valiosos para o "mercado", verificamos que há sempre o risco de uma divisão social do trabalho que tende a afirmar a supremacia daqueles que ocupam o topo do controle do trabalho em rede. Kreimer (2010) compreende isso como o resultado um processo de "internacionalizaçáo forçada" que, em curso desde os anos 90 do século XX, obriga pesquisadores dos países periféricos do capitalismo a adentrarem em programas de pesquisa, sobretudo científico-industriais, já estabelecidos por líderes dos grupos hegemônicos, em uma configuração de poder que impede os pesquisadores da "periferia" de verdadeiramente avançarem no desenvolvimento de seus próprios interesses cognitivos. Para o autor, as agendas e a definição do que se pesquisa são controladas

[...] pelas relaçóes entre os lideres dos grupos hegemônicos, as agências nacionais ou supranacionais e as empresas privadas localizadas nos paises desenvolvidos. Nesse processo, os lideres dos grupos nos contextos periféricos somente são convocados "no último momento" ["qu'après coup"] para realizar tarefas por vezes muito sofisticadas, mas cuja definição lhes escapam inteiramente. (KREIMER, 2010, p. 119).

A discussão empreendida neste artigo tem como referência as ciências humanas e sociais, especialmente o domínio da educação. Basta um breve olhar para os parcos montantes de financiamento dirigidos a essas ciências em comparaçáo com as "megaciências" para que concluamos que as políticas e dinâmicas de pesquisa diferem bastante, pois as "mega-ciências" estáo ligadas a uma forma de fazer política de conhecimento e inovação tecnológica que envolve grandes financiamentos por agências governamentais, principalmente dos países mais desenvolvidos. Mas isso não significa que a integração em redes internacionais em ciências humanas e sociais comporte sempre uma divisão de trabalho simétrica e horizontal. Também nas humanidades existe o risco de os grupos dos países periféricos ocuparem uma posição subordinada, como satélites complementarmente integrados ao centro do sistema, o que Kreimer (2006) denomina "ciência hiper-normal", ou seja, uma produção de conhecimento que apenas reproduz os temas de interesse dos grupos e instituiçôes dominantes nos países desenvolvidos, o que ocorreria com um nível de inovação muito baixo em relação ao que se faz nos países centrais, ainda que com alto valor quanto aos dados gerados.

Porém, como a comercialização dos resultados das pesquisas é um elemento forte nas "mega-ciências", isso aguça a concorrência e a disputa entre pesquisadores muito mais do que nas ciências humanas e sociais, cujos produtos mais valorizados são 
os artigos, os livros, as teses e os congressos. Todavia, o que as advertências de Kreimer (2006, p. 200) contêm de maior importância para nos é a sua afirmação da necessidade de que prestemos "atenção às modalidades de relação internacional que tem estabelecido os cientistas locais com os grupos de maior significação em cada um dos campos disciplinares".

É visível no âmbito das pesquisas em educação a maior visibilidade internacional de pesquisadores europeus e estadunidenses, tidos como competentes por desenvolverem programas de pesquisa sólidos e reconhecidos pela comunidade acadêmica. Entretanto, as formas como os saberes do "centro" são apropriados pela periferia e participam das agendas e dos temas de pesquisa dependem de diferentes fatores que não podem ser resumidos à noção de uma relação pura e simples de colonialismo intelectual e político.

No caso dos pesquisadores de ciências humanas e sociais, a posição menor na relação com parceiros internacionais mais experientes pode ser temporária, até que a coletividade local de pesquisadores ganhe condições e competências suficientes para assumir a coordenaçáo de projetos mais exigentes do ponto de vista de sua execuçáo e, desse modo, cada vez mais se despregue de divisóes de trabalho em que ocuparam condição social de aprendiz. Contudo, para que tal ocorra, faz-se necessária a existência de condiçóes de trabalho docente e políticas de financiamento de pesquisa que facilitem isso.

Sabemos da existência de concorrência para o acesso aos recursos dirigidos à pesquisa, visto que os financiamentos sáo escassos, colocando em ação mecanismos competitivos em termos de controle do capital simbólico que dá acesso ao reconhecimento de competência individual e coletiva, segundo os valores que orientam a produção da pesquisa em cada um dos seus domínios do conhecimento. Atualmente, esses valores são expressos por procedimentos de julgamento de competência dos pesquisadores e da qualidade dos projetos, tais como a adequaçáo dos projetos às exigências das agências de financiamento de pesquisa, a avaliação por pares na seleção dos projetos de pesquisa e das publicaçóes e o impacto da produçấo no terreno científico.

De um lado, os pesquisadores submetem-se aos julgamentos críticos de seus pares quando difundem seus trabalhos na comunidade acadêmica. De outro lado, são submetidos à avaliação no seio de instituiçôes diversas, ligadas ao conhecimento e ao trabalho de pesquisa, cuja valorização segue critérios apresentados como científicos (construir conhecimento inovador), pedagógicos (divulgar o conhecimento gerado) e sociais (ajudar na resolução de questóes sociais), em um processo crescente de regulação do sistema universitário a partir dos critérios que norteiam a produção científica 
atualmente. Esses elementos de julgamento externos são apropriados, em maior ou menor grau, no interior de cada domínio do conhecimento, bem como pelos grupos de pesquisa locais, no jogo de reconhecimento de competência do campo científico, mas sem desconsiderar as políticas de financiamento de pesquisa vigentes.

Em consonância com essa lógica, as redes de pesquisa local que buscam a participação internacional do ponto de vista político são constituídas com o objetivo de ganhar visibilidade internacional e, ao mesmo tempo, granjear maior reconhecimento acadêmico ao exibir um maior domínio de seu campo disciplinar em seu próprio país (KREIMER, 2006, 2010), o que geralmente aumenta o impacto dos trabalhos desenvolvidos. No interior dessa dinâmica, os pesquisadores apropriam-se dessas referências e estruturam suas próprias práticas de valorização de seus trabalhos e dos outros, em um jogo que compreende, simultaneamente, a cooperação e a competição.

\section{Divisão do trabalho colaborativo: relações entre o disciplinar e o transdisciplinar na produção do conhecimento}

Uma rede de pesquisa em humanidades pode se organizar em torno de uma perspectiva teórico-metodológica única e homogênea no tratamento de diferentes objetos de conhecimento ou primar pela possibilidade da inter ou transdisciplinaridade, que permite ultrapassar conhecimentos setoriais ou abordagens específicas. Como exemplos do primeiro caso, podemos elencar os pesquisadores que tratam de diferentes objetos a partir de uma única teoria de referência (e dos seus desdobramentos metodologicos), como a psicologia sócio-histórica, a teoria do ator rede ou a teoria crítica da sociedade. No segundo caso, a investigação pode ser realizada no cruzamento dos estudos originários do interior de vários domínios do saber, como, por exemplo, da antropologia e da educação, da sociologia e da psicologia social, da sociologia da infância e da sociologia da juventude etc. Além disso, redes que abrangem campos ou objetos de pesquisas menores (mais circunscritos) podem ser ligadas a redes maiores, porém com foco em um tema comum (como, por exemplo, a infância, a educação infantil etc., ou seja, um assunto que se deseja investigar) e/ou um problema de investigação (a dimensão a ser pesquisada, ou seja, o aspecto que se quer desenvolver dentro de uma área temática para conhecer ou inovar o conhecimento existente).

No entanto, independentemente de qual seja o modelo de referência, as redes são consideradas como organizaçôes relacionais avançadas para o desenvolvimento e a consolidação da pesquisa, sobretudo quando as suas trocas se fazem também com o exterior, com a participação de professores/pesquisadores estrangeiros, de maneira a 
abordar diferentes objetos e campos de conhecimento de forma mais inclusiva e comparativa.

Dada a importância de considerar como o conhecimento é gerado no interior do domínio focado, vale lembrar que o campo da educação no Brasil é multidisciplinar (no sentido mais simples do termo, ou seja, conta com diferentes áreas). Mas, embora a multidisciplinaridade possa ser um fator enriquecedor da cooperação, na medida em que os pesquisadores, ao menos em tese, podem perceber como cada disciplina trata epistemologicamente seus objetos, no cenário nacional e internacional a transdisciplinaridade permite não apenas o diálogo, mas também o atravessamento das fronteiras disciplinares constituídas, em funçáo dos desafios colocados pelo objeto de investigação, o que favorece diferentes níveis de integração e articulação dos conhecimentos.

A perspectiva transdisciplinar implica uma expectativa diferente da disciplinar diante da organização do trabalho no interior da equipe dada pela apropriação mais igualitária do saber que ela permite. A transdisciplinaridade permite a mobilização de teorias provenientes de diferentes domínios do saber para dar conta de objetos de pesquisa multifacetados, que podem ganhar complexidade por um trabalho de integração da reflexão, rumo a um pensamento organizador que ultrapassa as fronteiras disciplinares em busca de novas sínteses.

A pesquisa transdisciplinar pode incluir preocupaçôes metodológicas, mas não pode ser confundida com um método ou uma nova organização do conhecimento ou da divisão das tarefas no interior do grupo de pesquisa. Ela procura dar conta daquilo que não foi possível compreender a partir dos conhecimentos gerados no interior das especializaçôes disciplinares. Entretanto, se de um ponto de vista pragmático assumimos que os objetos de pesquisa apresentam diferentes níveis de complexidade e que nem todos os objetos requerem uma abordagem transdisciplinar, podemos pensar em projetos de pesquisa de diferentes tipos de orientação epistemológica. Ou seja, um mesmo projeto pode ter uma parte de forte feição disciplinar e outra interdisciplinar ou multidisciplinar, a depender dos pontos de tensão e incerteza que levem a uma problematização contundente dos aspectos pesquisados. As partes não problematizadas do projeto podem seguir uma orientaçấo disciplinar até o momento em que ganhem um novo valor como resultado do questionamento da compreensão estabelecida sobre um objeto de pesquisa. Portanto, adotar a transdisciplinaridade não significa a interdição de divisôes de trabalho ou alguma especialização, dependendo do que é considerado o núcleo mais crítico do projeto. É possivel que cada um se responsabilize por uma parte ou por diversas partes diferenciadas do projeto coletivo como totalidade (tal como quando uma mesma pesquisa é aplicada a diferentes contextos, de maneira 
que um subgrupo se aprofunde em um contexto, outro em mais de um contexto, resultando que os dados permitam comparaçóes entre dinâmicas e âmbitos de investigação). $\mathrm{O}$ importante é uma abertura do pensamento ao objeto em suas múltiplas facetas, em busca de novas sínteses, de maneira que este se constitua em meio aos vários pontos de vista que ganharam significação no coletivo transdisciplinar que o problematizou.

\section{O trabalho em redes e grupos de pesquisa: formatos do projeto e dinâmicas relacionais}

Para complementar esta discussão, faz-se necessário ter em conta que, para se constituir efetivamente, um grupo interuniversidades local/internacional deve negociar um problema de pesquisa e uma agenda comum, o que implica levar em conta o processo de transposição de um tema de interesse em um problema de investigação compartilhado, inclusive uma organização do trabalho orientada para o desafio de integração das açóes individuais e grupais no coletivo em colaboração.

Conforme os objetivos deste artigo, a integração das ações dos pesquisadores para a colaboração interuniversitária em pesquisa foi pensada a partir de um coletivo maior e de interesse mais amplo, a rede de pesquisadores, e de coletivos menores em seu interior, os grupos de pesquisa. Trata-se de um formato que concebe diferentes níveis e graus de colaboração, do mais geral e inclusivo ao mais específico, de modo que a coparticipação pode ocorrer entre e dentro de diferentes níveis.

Nessa perspectiva, o nível mais inclusivo e geral é o da rede, quando consideramos que uma rede de pesquisa pode ser definida como uma organizaçáo de diferentes indivíduos ou grupos com interesses temáticos de investigação em comum, cujo alvo é a produção conjunta de conhecimento. O grau de participação de cada parte participante é flexível, inclusive permitindo a utilização frequente de recursos que encurtam distâncias, tais como ferramentas de colaboração online. Mais comumente, os vínculos entre pesquisadores são estabelecidos e alimentados por meio de projetos interinstitucionais, tais como a formação de coletivos de pesquisa, a participação em bancas de avaliação, o envolvimento em programas e cursos de ensino de feição interinstitucional, a participação em simpósios, seminários e congressos etc.

Grupo de Pesquisa é a denominação atribuída ao grupo de pesquisadores e estudantes que se organizam em torno de uma área do conhecimento, com o objetivo de aumentar a compreensão dos fenômenos abarcados por ela, que supôe um laço social mais forte entre os seus participantes, um envolvimento profissional e permanente com a atividade de pesquisa, geralmente organizado ao redor de linhas de pesquisa com pontos em comum e, em algum grau, são compartilhadas instalaçóes e equipamentos. 
A rede liga indivíduos e grupos em seu interior de uma maneira mais leve, de forma que o laço entre eles pode ser mais frouxo. Como o envolvimento requerido na participação de redes de pesquisas é menor do que no grupo de pesquisa, pesquisadores/estudantes podem participar de várias redes de pesquisa, mas é considerada indesejável (condição atípica para o $\mathrm{CNPq}$ ) a participação em muitos grupos de pesquisa (no máximo em três grupos de pesquisa para pesquisadores e em um para estudantes) e em grupos de pesquisa numerosos (com mais de 10 pesquisadores, segundo o $\mathrm{CNPq}$ ). O ideal que orienta essa posição é que de fato se constitua uma proximidade relacional permanente e estável entre os participantes do grupo de pesquisa. Isso significa que a rede pode ter mais flexibilidade e potencialidade de crescimento maior do que o grupo de pesquisa, pois no seu interior ela pode congregar indivíduos, grupos e redes menores.

Quando focalizamos a cooperação que envolve pesquisador/estudantes de programas de pós-graduaçôes, sabemos que geralmente é mais fácil deflagrar a produçáo científica por meio de açóes internas a cada um deles. A razão principal é que para atuar em redes de cooperação interuniversitárias se faz necessário um engajamento em novas tarefas, o que requer um incremento na organização das atividades cotidianas, inclusive de gestáo do projeto, voltadas para a relação com os grupos colaborativos de cada uma das universidades participantes etc. Além disso, para os iniciantes a colaboração em coletivos de pesquisa interuniversitários implica lidar com muitas tarefas novas e desconhecidas. Em meio a isso, o estabelecimento de um trabalho colaborativo provoca, como toda ação que não tem um lugar definido nas rotinas acadêmicas, sobrecarga de trabalho, desconhecimento do processo completo do trabalho, certo temor de não conseguir levar as tarefas até o fim, de ter de realizar trabalhos de outrem etc. Então, como minimizar o desajuste entre as diferentes atividades que compóem a agenda de professor pesquisador e o calendário de pesquisa que acordamos no interior do grupo colaborativo?

Defendo o estabelecimento de um contrato de trabalho com uma autonomia relativa entre os subprojetos e o projeto mais amplo que o grupo se propóe a desenvolver, visto que o risco de um trabalho (transdisciplinar e/ou disciplinar) em que todos desenvolvem o mesmo projeto, sem divisáo de tarefas ou de subprojetos no seu interior, é que se uma parcela dos pesquisadores não consegue cumprir a sua parte, por vezes os outros devem substituí-los, sob o risco de fracasso do trabalho coletivo. Uma forma de levar isso em consideração é trabalhar com a ideia de que o trabalho conjunto, para alcançar os objetivos comuns a um trabalho de colaboração interuniversitária em pesquisa, sobretudo de caráter iniciante, poderia partir do pressuposto do comprometimento e envolvimento diferenciado entre os parceiros. 
Além disso, uma das formas de diminuir esses problemas consiste em refletir bastante no momento da escolha da modalidade de projeto a ser desenvolvida. Tenho uma ligeira preferência pelos projetos "guarda-chuva", pois permitem dar conta da heterogeneidade de interesses e de formação, além de facultarem que cada segmento no interior de um grupo colaborativo tenha uma autonomia teórico-metodológica grande em relação à totalidade dos pesquisadores que empreendem a pesquisa compartilhada.

Os projetos "guarda-chuva" são também chamados de integrados, na medida em que um projeto maior é articulado e/ou desdobrado em outros (sub)projetos, que podem ser desenvolvidos entre profissionais e estudantes de diferentes instituiçôes. Assim, os subprojetos ou projetos desdobrados mostram as suas relaçôes com o projeto maior ("guarda-chuva") do ponto de vista dos temas abordados, das dinâmicas teóricometodológicas e/ou dos procedimentos de investigação. Desse modo, geralmente os projetos são coordenados por um ou dois pesquisadores, apresentam maior abrangência e duração, incluindo subprojetos com recortes da temática geral e equipes de execução distintas.

Um dos desafios de ordem prática remete à integração interna de uma equipe recém-constituída, algo que pode se dar por diferentes maneiras. Uma delas consiste no desenvolvimento de um primeiro projeto, com caráter de pesquisa exploratória, com vista a proporcionar maior familiaridade com as diferentes nuances da problemática abordada, explicitar melhor a abordagem e aperfeiçoar os procedimentos teóricometodológicos, bem como retomar as hipóteses iniciais e/ou o estabelecimento de novas relaçóes entre variáveis. Ao mesmo tempo, o grupo reconhece e amplia as suas competências, podendo reconfigurar o projeto e a divisão do trabalho no interior de sua equipe para fazer frente aos desafios visualizados na execução dessa primeira entrada no trabalho compartilhado.

Outra forma é a produção de uma pesquisa com um núcleo duro compartilhado, para permitir a comparação dos dados, conjugado a outras partes voltadas para a investigação de elementos que são objetos de interesses específicos de indivíduos e grupos que se engajam na pesquisa coletiva, mas que têm também objetivos e focos de pesquisa particulares.

Conforme o modelo adotado, os resultados projetados para um trabalho de colaboração podem ser integrados de diferentes maneiras. A totalidade do resultado pode ser muito dependente de trabalhos parciais ou intermediários, divididos entre diferentes grupos e indivíduos, ou, de modo diferente, cada um dos trabalhos pode ser visto como desdobramento de uma totalidade, em que cada um tem uma unidade específica, mas cuja totalidade não exige a integração de todos os trabalhos parciais ou intermediários para o sucesso do projeto coletivo. Nesse caso, certas partes podem ser 
destacadas da totalidade, e vice-versa, sem ameaça de destruição do trabalho da equipe. Porém, faz-se importante atentar para o nível de abrangência e profundidade permitido pelos trabalhos, pois os participantes, ou uma parte deles, podem ter expectativas distintas diante das diferentes situaçóes de pesquisa em que se engajam.

Em projetos financiados, segundo uma modalidade de pesquisa em que todos os pesquisadores devem obrigatoriamente se responsabilizar por uma parte sem a qual o trabalho total fica mutilado, é grande a responsabilidade dos coordenadores em lidar com possíveis obstáculos, como a impossibilidade de um subgrupo em particular ou de um determinado pesquisador realizar a parcela da pesquisa sob sua responsabilidade. Esse tipo de situação exige que os coordenadores conheçam muito bem o conjunto das atividades repartidas de maneira a encontrar meios de assegurar a execução das partes imprescindíveis à totalidade do trabalho.

Por outro lado, existem pesquisas nas quais cada subprojeto poderá empregar seu método científico específico na investigação, guardando uma enorme autonomia relativa em relação ao projeto global. Ou seja, a linha de raciocínio adotada na formulação dos projetos de pesquisa é que elemento fornece as bases lógicas da investigação e as suas formas de integração ao projeto global. Dessa maneira, são muito importantes na definiçấo dos modelos mais indicados para o desenvolvimento de uma pesquisa partilhada as perguntas que cada subprojeto almeja responder e o aporte que ele fornece ao projeto mais amplo ao auxiliar na resposta de questóes que transcendem os seus recortes específicos.

As exigências impostas pelo trabalho de colaboração dependem também do tipo de pesquisa proposto. Pesquisas bibliográficas podem engendrar formas de colaboração diferentes daquelas que envolvem trabalho de campo; o mesmo se pode dizer a respeito das pesquisas em territórios virtuais (internet), pois estas constituem, pelo menos em parte, procedimentos de produção de investigação em equipe com formatos diversos dos usados em contextos não virtuais.

A situação que exige mais de todos os pesquisadores é aquela em que os participantes devem realizar, em um tempo rigidamente determinado, um conjunto de atividades que devem ser submetidas ao julgamento externo. Para alguns, o trabalho pode tornar-se prisioneiro do imperativo da apresentação imediata dos resultados, havendo divisão entre aqueles que pensam ser importante se submeter de maneira inconteste a esse imperativo e aqueles que a ele aderem com reservas. Em meio a isso, a participação pode ser vista apenas como uma obrigação, por falta de engajamento real ou por um enfraquecimento da adesão por motivos diversos (tais como a crítica ao imperativo dos resultados imediatos e discordância em relaçáo à divisão do trabalho estabelecida), inclusive uma oportunidade para realização de outros objetivos, 
individuais ou coletivos. Ou pode, em contrapartida, ser uma oportunidade única de ampliação da formação social e profissional de produção de novos conhecimentos e de contribuição para a resolução de questôes sociais, além de favorecer o reconhecimento coletivo e individual de todos os que contribuíram para isso.

Diante da exigência de divulgação, conhecida pela expressão "publique ou morra", pesquisadores, universidades e instituiçóes de pesquisa mobilizam-se para gerar produtos que possam ser objetos de muitas divulgaçóes públicas antes mesmo da finalização do processo de investigação, ou seja, a publicação de conhecimentos parcelares deve ocorrer até que a pesquisa produza um artigo verdadeiramente original, já que deixar para publicar somente quando houver o desenvolvimento de conhecimento de peso pode implicar dificuldade em continuar a receber financiamento de projetos e, até mesmo, rotulação do pesquisador ou do grupo como improdutivo ou pouco produtivo. Se na era contemporânea conhecimento consolidado é conhecimento publicado, o imperativo de publicação pode levar à exposição de conhecimento não suficientemente consolidado, o que não deixa de ter consequências sociais e acadêmicas caso o nível de consolidação atingido não seja suficientemente explicitado.

Que a divulgação dos resultados da pesquisa é fundamental todos concordam; porém, a questáo é a corrida que o modelo promove quando torna a publicação o mais importante indicador de reconhecimento social de pesquisadores, de instituiçóes universitárias e de pesquisa. Dessa maneira, cada vez mais a divulgação da pesquisa na forma de publicação tem sido um dos mais importantes critérios de avaliação dos programas de pós-graduação e da qualidade da universidade e todos os pesquisadores se veem impelidos a publicarem em um ritmo cada vez mais acelerado.

Atualmente, entre as publicaçóes, o artigo é mais valorizado do que a publicação de livro (ou capítulo) na divulgaçáo científica. No interior dessa dinâmica, as colaboraçôes em pesquisas são valorizadas em termos de sua quantificação em publicaçóes de artigos em coautoria. Isso pode estimular autores a estabelecerem colaboração para publicarem juntos a partir de uma lógica de troca e partilha real de conhecimento e experiências ou apenas por acordos estratégicos para aumentar a quantidade de publicação de cada um deles.

Diante de tudo isso, a produção da pesquisa deve levar em conta não somente os meios para atingir certos resultados, mas também suas adequaçóes a outros propósitos perseguidos pelos participantes da equipe de trabalho. Picotar o conhecimento (aumentando a sua fragmentação) para que ele caiba em artigos - pois a publicação do livro vale pouco pelas regras da avaliação da produção vigente - é uma escolha posta para todos nós. Se o tempo é exíguo para a publicação de um livro e o artigo tem mais 
valor, torna-se difícil apresentar a totalidade de um trabalho, com toda a riqueza que ela possa oferecer.

\section{Considerações finais}

Apesar das iniciativas governamentais e da valorização acadêmica, a pesquisa interuniversidade ainda permanece um desafio como prática efetiva, pois é a mobilização das universidades e dos pesquisadores que determina a colocação na ordem do dia das pesquisas em parceria e, acima de tudo, as formas de participação possíveis. Isso porque, embora as pesquisas colaborativas interuniversidades sejam promissoras no avanço do conhecimento e no ganho de experiência daqueles que dela participam, geralmente há exigências árduas para a sua realização no campo das humanidades. Além disso, a infraestrutura e os recursos disponibilizados por cada universidade são fundamentais para a promoção do intercâmbio com pesquisadores externos, especialmente com aqueles vinculados a universidades estrangeiras - o que depende de inúmeros fatores de ordem conjuntural. Por essa razão, faz-se importante destacar a importância da ampliação do debate sobre as reais condiçôes de produção de conhecimento, expressas condiçốes de trabalho e também em termos de financiamento disponíveis, para que ocorra mais efetivamente a inserção internacional dos pesquisadores das humanidades.

O objetivo deste artigo foi problematizar o processo que se dá quando coletivos distintos juntam esforços para colaboração em um projeto de investigação comum, o que pode se dar em diferentes níveis, conforme o tema de pesquisa, o foco e a abrangência do trabalho, o tempo disponível para o desenvolvimento das tarefas, as diferenças de experiências entre os participantes, os recursos disponíveis etc. Porém, um aspecto crucial da pesquisa colaborativa, que inclusive constitui um dos indicadores $\mathrm{da}$ qualidade da co-construção da pesquisa e do seu sucesso, é o grau de adesão mútua ao "trabalhar juntos", ou seja, o nível de implicação no trabalho coletivo.

Em médio e em longo prazo, as colaboraçôes são potencialmente sujeitas a mudanças de diferentes tipos, como a entrada e saída de novos parceiros, modificação nos financiamentos, prazos e recursos, mudanças nas escalas dos projetos etc. Ou seja, uma rede ou grupo de pesquisa não se estabelece de uma vez por todas, bem como os recursos que podem lhe dar sustentação. Isso significa que sempre existem coisas a serem aprendidas do ponto de vista organizativo e relacional, ao mesmo tempo em que o engajamento no trabalho em rede implica renovar e enriquecer o grupo e simultaneamente facilitar o desenvolvimento individual de cada um.

Espero que este artigo contribua para a ampliação do conhecimento sobre o assunto e encoraje os pesquisadores a organizarem coletivos capazes de aumentar o 
conhecimento social e oferecer subsídios para a resolução de questóes sociais, apesar dos complexos obstáculos existentes dentro e fora das universidades.

\section{Nota}

${ }^{1}$ Trata-se de um projeto de cooperaçáo baseado na ideia de redes de trabalho com divisão das tarefas para a troca de conhecimento e resultados, com diversos propósitos, tais como: pesquisas em grupo, formação dos estudantes de pós-graduação, estudos comparativos de educação em nível internacional e assim por diante. O projeto avançou significativamente depois que recebeu suporte financeiro do CNPQ, no período de 2011 a 2013.

\section{REFERÊNCIAS}

CASTELLS, Manuel. A sociedade em rede. São Paulo: Paz e Terra, 1999.

DUBET, François. A Sociologia da experiência. Lisboa: Instituto Piaget, 1994.

KREIMER, Pablo. ¿¿Dependientes o integrados? La ciencia latinoamericana y la nueva división internacional del trabajo. Nómadas, Bogotá, n. 24, p. 199-212, abr. 2006. Disponível em: <http://www.redalyc.org/articulo.oa?id=105116598017>. Acesso em: 22 maio 2014.

KREIMER, Pablo. La recherche en Argentine: entre isolement et dépendance. Cahiers de la recherche sur l'éducation et les savoirs, Paris, v. 9, p. 115-138, 2010. Disponível em: <http://cres.revues.org/401>. Acesso em: 19 maio 2014.

MARRARA, Thiago. Internacionalização da pós-graduação: objetivos, formas e avaliação. Revista Brasileira de Pós-Graduação, Brasília, DF, v. 4, n. 8, p. 245-262, 2007. Disponível em:

<ojs.rbpg.capes.gov.br/index.php/rbpg/article/download/132/126>. Acesso em: 19 mar. 2014. 


\section{The work in collaborative research networks and groups: contemporary challenges}

\begin{abstract}
The paper presents a reflection about interuniversity collaboration in national and international networks and research groups in contemporary society, with emphasis on their value, their dilemmas and challenges posed to people and groups participating in it. The work stems from the assumption that Brazilian academic scenario requires the teacherresearcher to adjust his/her personal interests to the collective ones of researchers and at the same time, to respond the requirements arising from the competitive model that guides the scientific production nowadays. Taking this into consideration, the paper tries to subsidize those interested in determining the collaborative research and the types of projects, contribute to organize the division of labor within the research teams, and perhaps encourage collective of researchers to undertake collaborative projects. The methodological reference of the research was the social network analysis, bibliographic studies and reflections on everyday research group practice within the university scientific production, including the experience from the author of this article into a collective that aimed to establish an inter-university network education research.
\end{abstract}

Keywords: Research Networks. Scientific Collaboration. University.

\section{El trabajo en redes y grupos de colaboración en investiga- ción: desafíos contemporá- neos}

\section{Resumen}

El artículo se centra en la colaboración interuniversitaria en redes y grupos de investigación nacionales e internacionales en la sociedad contemporánea, con énfasis en su valor, sus dilemas y desafíos que plantean a las personas y grupos que participan en él. El trabajo parte del supuesto de que el contexto académico brasileño requiere por parte del docente investigador realizar ajustes que lo lleven del interés personal al colectivo de investigadores y al mismo tiempo cumplir con las exigencias derivadas del modelo competitivo que guía la producción científica en la actualidad. Tomando esto en consideración, el interés es subsidiar a los interesados en la investigación colaborativa, los tipos de proyectos y contribuir con la organización de la división del trabajo dentro de los equipos de investigación, y quizás, animar a los investigadores a llevar a cabo proyectos de investigación compartida. La referencia metodológica de la investigación fue el análisis de redes sociales, los estudios bibliográficos y reflexiones sobre la práctica cotidiana del grupo de investigación universitaria, incluyendo la experiencia de inserción del autor de este artículo en un colectivo con el objetivo de constituir una red interuniversitaria de investigación en educación.

Palabras claves: Redes de Investigación. Colaboración Científica. Universidades. 
Ruth Bernardes Sant'Ana

E-mail: ruthbs@ufsj.edu.br

Recebido em: 10/9/2014 Aprovado em: 24/5/2015 